\title{
SENSITIVITY OF STEREOTOMOGRAPHY IN RELATION TO THE REGULARIZATION PARAMETERS
}

\author{
Josimar Roberto da Silva ${ }^{1}$, Jessé Carvalho Costa² and Amin Bassrei
}

\begin{abstract}
Migration is one of the most important steps in seismic processing because it is responsible for retrieving the existing geometric relationships in reflection events that are due to the existence of dips or irregularities at interfaces with different acoustic impedances. Thus, the seismic section is closer to reality, considerably facilitating the task of interpretation. However, to be successful, migration requires an accurate velocity model from the area to be imaged. Thus, in addition to being important, migration is usually the most complicated stage of seismic processing, especially in geologically complex areas. Stereotomography is a robust method for estimating velocity macro-models from seismic reflection data and is an alternative to velocity analysis, which is based on the stacking velocity. Occasionally, velocity analysis is not efficient enough to determine satisfactory velocity models. In addition to traveltime picking in locally coherent reflection events, the stereotomography method requires the local inclination associated with picked events simultaneously with common shot gathers and common receiver gathers. The data thus consist of a discrete set of traveltimes, shot and receiver positions, and inclinations for the selected reflection events. The objectives of this work are to apply stereotomography as a tool for generating velocity macro-models and to perform sensitivity analysis of stereotomography with regard to the so-called regularization factor or parameters. Various tests were performed with an extension of Marmousi data, called the Marmousoft model. The results clearly showed the variation in sensitivity of stereotomographic inversion for each type of regularization parameter used.
\end{abstract}

Keywords: stereotomography, seismic inversion, regularization, reservoir characterization.

RESUMO. A migração é uma das mais importantes etapas do processamento sísmico, pois é responsável por recuperar as relações geométricas existentes nos eventos de reflexão devido à existência de mergulhos ou irregularidades nas interfaces com diferentes impedâncias acústicas. Desta forma, a seção sísmica fica mais próxima à realidade, facilitando em muito 0 trabalho de interpretação. Contudo, para que a migração seja bem sucedida é necessário um modelo de velocidades bem apurado da área a ser imageada. Assim, além de ser importante, a migração é geralmente a etapa mais complicada do processamento sísmico, principalmente em áreas geologicamente complexas. A estereotomografia é um método tomográfico robusto para estimar macromodelos de velocidade a partir de dados sísmicos de reflexão e surge como uma alternativa à análise de velocidade, que é baseada na velocidade de empilhamento. Por vezes a análise de velocidade não é eficiente na determinação de modelos satisfatórios. Em adição à marcação dos tempos de trânsito nos eventos de reflexão localmente coerentes, o método da estereotomografia requer a inclinação local associada aos eventos marcados, simultaneamente, nos traços de famílias de tiro comum e de receptor comum. Os dados então consistem de uma coleção discreta de tempos de trânsito, posições de tiros e receptores, e inclinações para os eventos de reflexão selecionados. Os objetivos deste trabalho são a aplicação da estereotomografia como uma ferramenta para a geração de macromodelos de velocidades, e a análise de sensibilidade da estereotomografia aos chamados fatores ou parâmetros de regularização. Vários testes foram realizados com uma extensão dos dados Marmousi, chamado de modelo Marmousoft. Os resultados obtidos mostraram de forma clara a variação da sensibilidade da inversão estereotomográfica para cada tipo de parâmetro de regularização utilizado.

Palavras-chave: estereotomografia, inversão sísmica, regularização, caracterização de reservatórios.

\footnotetext{
1 Universidade Federal da Bahia, Institute of Geosciences - E-mail: josimarroberto90@hotmail.com

2Universidade Federal do Pará, Faculty of Geophysics and National Institute of Science and Technology in Petroleum Geophysics - E-mail: jesse@ufpa.br

${ }^{3}$ Universidade Federal da Bahia, Institute of Geosciences, Research Center in Geophysics and Geology, and National Institute of Science and Technology in Petroleum Geophysics, Rua Barão de Jeremoabo, s/n, Ondina, 40170-115 Salvador, BA, Brazil. Phone: +55(71) 3283-8508 - E-mail: bassrei@ufba.br
} 


\section{INTRODUCTION}

Stereotomography is an alternative to velocity analysis based on stacking velocity, which has proven to be a robust method for estimating macro-model velocities from reflection seismic data. In addition to traveltime picking of locally coherent reflection events, the method requires the local inclination associated with picking events, in both families of common-shot gathers and common-receiver gathers. The data then consist of a discrete set of traveltimes, positions (of shots and receivers) and slopes for the selected reflection events. Unlike standard traveltime tomography, only picking is required for locally coherent events. In fact, for the model description, the method does not require information on the interfaces. Many tomography approaches using the slope have been proposed. Stereotomography has a formulation based on a model described by a velocity field and a set of pairs of ray segments associated with reflected or diffracted events, which involves adjusting all observed data to the data calculated by ray tracing. It is important to stress that there are no theoretical limitations on stereotomography for lateral velocity variations.

The set of synthetic data used in the computer simulations was the Marmousoft set, which was adapted from Marmousi data. This dataset was created by the French Petroleum Institute to be used in the European Association of Exploration Geophysicists meeting in 1990. Marmousoft was adapted by Billete and Lambaré (1998) using ray modeling with Born approximation from a data set free of multiples and refractions. It is a combination of a smoothed velocity field and complex reflectivity.

Stereotomography belongs to the family of inclination tomography methods (Riabinkin, 1957; Sword, 1987; Billette \& Lambaré, 1998). The basis of these methods is to recognize that any locally coherent event in the not migrated pre-stacked domain, characterized by its traveltime and inclinations, can provide information on the velocity model.

The implementation of stereotomography demands the use of regularization by derivative matrices, which in turn uses a set of regularization parameters. In this work, the value of each regularization parameter is varied gradually, keeping the other parameters constant. The objective is to analyze the influence of each regularization parameter in the solution of the inverse problem. The behavior of the estimated model parameters is analyzed through the RMS data error, and the absolute error is computed in terms of slowness, position and traveltime. Moreover, for a better visualization of the variation effects in these parameters, we present the images of the RMS error between the true and estimated velocities.

\section{INVERSE PROBLEMS, LINEARIZATION REGULARIZATION AND L-MODULE}

Inversion is a technique that estimates the parameters of a given model using the observed data as an input. On the other hand, forward modeling provides such data by assuming a synthetic model. While the output of the forward problem is theoretically unique, inverse problems show an inherent ambiguity in the conclusions that can be obtained.

The information description is used as the starting point when analyzing geophysical data. A vector provides a practical representation of these values: $\boldsymbol{d}=\left[d_{1}, d_{2}, \ldots, d_{M}\right]^{T}$ is the vector of observed data parameters or simply observed data. The vector of model parameters, or simply model, is represented by $\boldsymbol{m}=\left[m_{1}, m_{2}, \ldots, m_{N}\right]^{T}$. For the linear problem, the equation $\boldsymbol{d}=\boldsymbol{G} \boldsymbol{m}$ represents the solution of the forward problem, and $\boldsymbol{m}^{\text {est }}=\boldsymbol{G}^{-1} \boldsymbol{d}$ represents the solution of the inverse problem. To solve an inverse problem, we must analyze the existing issues, uniqueness and stability. If one of these conditions fails, the problem is said to be ill-posed.

The method of linearization starts from an initial model, $\boldsymbol{m}_{o}$, which is updated successively and is also known as the GaussNewton method. It linearizes the nonlinear problem $\boldsymbol{g}(\boldsymbol{m})=\boldsymbol{d}$ around an approximate solution. The estimated model is then obtained iteratively by solving a system of linear equations at each step. This method will converge to the model associated with the cost function closer to $S\left(\boldsymbol{m}_{o}\right)$ (Menke, 1989).

The expression to update the current model is:

$$
\left(\boldsymbol{G}^{T}\right)^{k} \Delta \boldsymbol{d}^{k}=\left(\boldsymbol{G}^{T} \boldsymbol{G}\right)^{k} \boldsymbol{\Delta} \boldsymbol{m}^{k},
$$

where $\Delta \boldsymbol{m}^{k}=\boldsymbol{m}^{k+1}-\boldsymbol{m}^{k}$ is the estimated model parameters update for the $k$-th iteration, $G^{k}$ is the tomographic matrix for the $k$-th iteration, and $\Delta \boldsymbol{d}^{k}$ is the data residual between the $k+1$-th and the $k$-th iterations.

Regularization techniques are applied in the numerical solution of discrete ill-posed problems to make the inversion more stable. The term regularization refers to different procedures to solve or at least to attenuate the ill-posedness of the inverse problem. For example, when using singular value decomposition, small singular values can be avoided in the construction of the pseudo-inversion, which will regularize the solution. In this work we used the regularization with derivative matrices, usually known in the literature as Tikhonov regularization or sometimes as Phillips-Twomey regularization. Besides the first and second order derivative matrices, the zero order regularization was also used simultaneously. The latter approach is usually known in the literature as damped least squares or Levenberg-Marquadt 
technique. The regularization by derivative matrices is expressed by the objective function $\varphi(\boldsymbol{m})$ :

$$
\varphi(\boldsymbol{m})=\boldsymbol{e}^{T} \boldsymbol{e}+\lambda L_{n},
$$

where $L_{n}$ is a discrete derivative operator that imposes some smoothing to the solution and $\lambda$ is a non-negative constant called the regularization parameter, which controls the amount of smoothing on the solution. We can use the difference between the physically adjacent model parameters as an approximation of the first derivative $(n=1)$ matrix expressed as $\boldsymbol{D}_{1}$. The operator, also known as flatness, will then be $L_{1}=\boldsymbol{m}^{T} \boldsymbol{D}_{1}^{T} \boldsymbol{D}_{1} \boldsymbol{m}$ (Menke, 1989). We can also use a matrix that approximates the second derivative $(n=2)$, expressed as $\boldsymbol{D}_{2}$. The operator, $L_{2}=\boldsymbol{m}^{T} \boldsymbol{D}_{2}^{T} \boldsymbol{D}_{2} \boldsymbol{m}$, is called roughness (Menke, 1989). The general expression for $L_{n}$, either flatness or roughness is given by:

$$
L_{n}=\left\|\boldsymbol{l}_{\boldsymbol{n}}\right\|_{2}^{2}=\left(\boldsymbol{D}_{n} \boldsymbol{m}\right)^{T} \boldsymbol{D}_{n} \boldsymbol{m},
$$

where $n$ is the order of the derivative matrix. By developing the Eq. (2) and using the appropriate substitutions $\boldsymbol{e}=\boldsymbol{d}-\boldsymbol{G} \boldsymbol{m}$ and $L_{n}=\left(\boldsymbol{D}_{n} \boldsymbol{m}\right)^{T} \boldsymbol{D}_{n} \boldsymbol{m}$, we have:

$$
\begin{gathered}
\varphi(\boldsymbol{m})= \\
\left(\boldsymbol{d}^{T}-\boldsymbol{m}^{T} \boldsymbol{G}^{T}\right)(\boldsymbol{d}-\boldsymbol{G} \boldsymbol{m})+\boldsymbol{\lambda}\left(\boldsymbol{D}_{n} \boldsymbol{m}\right)^{T} \boldsymbol{D}_{n} \boldsymbol{m} .
\end{gathered}
$$

For the linearized process, we started with a homogeneous initial model $\boldsymbol{m}^{0}$ and updated the model parameters iteratively through the following equation:

$$
\left(\boldsymbol{G}^{T} \boldsymbol{G}+\lambda \boldsymbol{D}_{n}^{T} \boldsymbol{D}_{n}\right)^{k} \boldsymbol{\Delta} \boldsymbol{m}^{k}=\left(\boldsymbol{G}^{T}\right)^{k} \boldsymbol{\Delta} \boldsymbol{d}^{k} .
$$

There are several methods presented in the literature to find the optimal regularization parameter $\lambda$. Among them, the Lmodule, which was proposed by Sá (1996), is based on the Lcurve. The concept of the L-curve is necessary to understand the L-module. The L-curve is a graphical tool used to choose the regularization parameter. One recent application of the L-curve in seismic inversion can be seen in Santos et al. (2006).

The abscissas correspond to the error vector between the observed and calculated data, $\|\boldsymbol{e}\|=\|\boldsymbol{G} \boldsymbol{m}-\boldsymbol{d}\|$. The ordinates correspond to the amount of regularization, $\left\|\boldsymbol{D}_{n} \boldsymbol{m}\right\|$. When displayed on a log-log scale, this curve usually resembles the shape of the letter $L$, where the inflection region represents the region of interest because it indicates the best regularization parameter. Thus, each point on this curve is the result of an estimated model by which its turn is related to $\lambda$, and the ideal point expresses the balance between the error and the regularization.
The L-module measures the distance of a point on the L-curve to the axes origin and is defined by the following equation:

$$
M o d L^{2}=\left[\boldsymbol{e}^{T} \boldsymbol{e}\right]^{2}+\left[\left(\boldsymbol{D}_{n} \boldsymbol{m}\right)^{T}\left(\boldsymbol{D}_{n} \boldsymbol{m}\right)\right]^{2}
$$

It is not necessary to construct the L-curve, and the interest region minimizes the $\mathrm{L}$-module. This method has another version if the input data are corrupted by noise:

$$
M o d L^{2}=\left[\boldsymbol{e}^{T} \boldsymbol{e}-\boldsymbol{r}^{T} \boldsymbol{r}\right]^{2}+\left[\left(\boldsymbol{D}_{n} \boldsymbol{m}\right)^{T}\left(\boldsymbol{D}_{n} \boldsymbol{m}\right)\right]^{2}
$$

where $\boldsymbol{r}$ is the vector that represents the noise in the data. When the noise level added in the data is unknown, an estimate may be used. Again, the curve must have a minimum.

\section{STEREOTOMOGRAPHY}

A set of stereotomography data $\boldsymbol{d}$ consists of a set of parameters corresponding to $M$ chosen locally coherent events. Each locally coherent event is represented by the following:

$$
\boldsymbol{d}^{T}=\left(\boldsymbol{s}, \boldsymbol{r}, T_{s r}, p_{s}, p_{r}\right),
$$

described by the positions of the source and the receiver, $s$ and $\boldsymbol{r}$, respectively, by the double traveltime, $T_{s r}$, and by the vertical inclination angles of the event in the directions of the common shot and common receiver, $p_{s}$ and $p_{r}$, respectively. This is what we call stereotomographic picking. Any event can be associated in a particular velocity model with a pair of rays parameterized by $\left(\boldsymbol{X}, \beta_{s}, \beta_{r}, T_{s}, T_{r}\right)$, where $\boldsymbol{X}$ indicates the reflector or diffractor position and $\beta_{s}$ and $\beta_{r}$ are the ray shooting angles for $\boldsymbol{s}$ and $\boldsymbol{r}$, respectively (Fig. 1).

In stereotomography, the cost function is the square of misfits in all data parameters of the data, that is, positions, vertical inclination angles and traveltimes. This introduces uncertainties in all parameters, and theoretically ensures the robustness of the local optimization (Billette \& Lambaré, 1998). As a consequence, the ray segment pairs must be optimized in conjunction with the velocity macro-model, thereby increasing the number of model parameters. Thus, the stereotomographic model is a combination of the velocity macro-model described by a set of velocity parameters $V_{j}$ and a set of ray segments pairs associated with each chosen event (Terra et al., 2012):

$$
\boldsymbol{m}=\left[\left(v_{j}\right)_{j=1}^{M},\left[\left(\boldsymbol{X}, \beta_{s}, \beta_{r}, t_{s}, t_{r}\right)_{i}\right]_{i=1}^{N}\right] .
$$

For any pair of ray segments and a priori velocity model, the set of stereotomographic parameters corresponding to a stereotomographic picking can be calculated. This calculation requires 


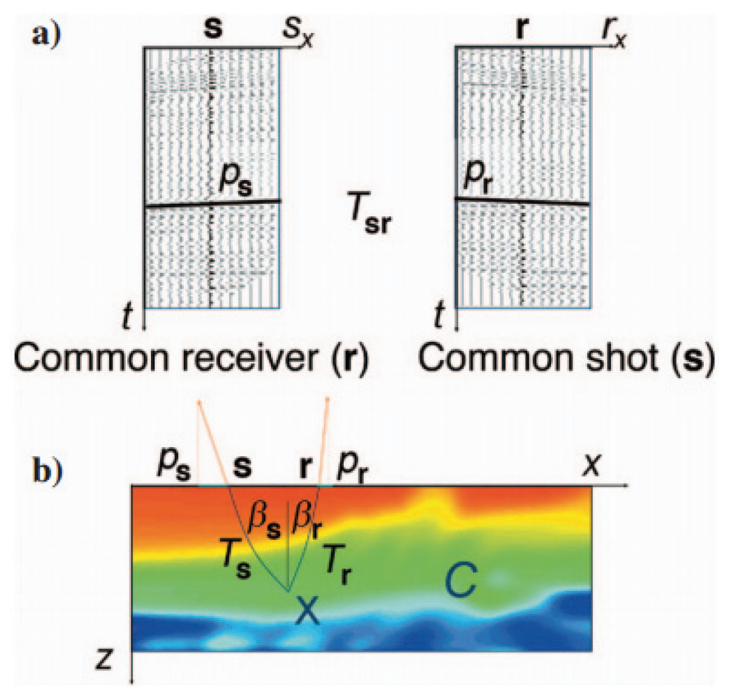

Figure 1 - (a) Stereotomography data: a locally coherent event in a pre-stacked data cube, characterized by its source and received positions $\boldsymbol{S}$ and $\boldsymbol{R}$ along the axis $s_{X}$ and $r_{X}$, vertical inclination angles and traveltimes. (b) Stereotomography model: a pair of ray segments displayed in the macrovelocity model characterized by reflector/diffractor point $\boldsymbol{X}$, angle shots in the directions of $\boldsymbol{s}$ and $\boldsymbol{r}$, and traveltime paths from $\boldsymbol{X}$ to $\boldsymbol{s}$ and to $\boldsymbol{r}$. Adapted from Lambaré (1998).

only two ray segments from the common point $\boldsymbol{X}$ toward the surface, with initial directions $\beta_{s}$ and $\beta_{r}$ and ray lengths corresponding to traveltimes $T_{s}$ and $T_{r}$. In this paper, we use an objective function (Costa et al., 2008):

$$
\begin{aligned}
& \varphi(\boldsymbol{m})=\left|\boldsymbol{d}^{\text {obs }}-g(\boldsymbol{m})\right|_{2}^{2}+\lambda_{D}^{2}\left|\left(\boldsymbol{m}-\boldsymbol{m}_{0}\right)\right|_{2}^{2} \\
& +\lambda_{L a p}^{2}\left|\left(\boldsymbol{D}_{1}^{2}+\boldsymbol{D}_{3}^{2}\right)\left(\boldsymbol{m}-\boldsymbol{m}_{0}\right)\right|_{2}^{2} \\
& +\lambda_{C 1}^{2}\left|\boldsymbol{D}_{1}^{2}\left(\boldsymbol{m}-\boldsymbol{m}_{0}\right)\right|_{2}^{2}+\lambda_{C 3}^{2}\left|\boldsymbol{D}_{3}^{2}\left(\boldsymbol{m}-\boldsymbol{m}_{0}\right)\right|_{2}^{2} \\
& +\lambda_{G 1}^{2}\left|\boldsymbol{D}_{1}\left(\boldsymbol{m}-\boldsymbol{m}_{0}\right)\right|_{2}^{2}+\lambda_{G 3}^{2}\left|\boldsymbol{D}_{3}\left(\boldsymbol{m}-\boldsymbol{m}_{0}\right)\right|_{2}^{2} \\
& +\lambda_{R}^{2} \boldsymbol{D}_{R}\left|\left(\boldsymbol{m}-\boldsymbol{m}_{0}\right)\right|_{2}^{2}
\end{aligned}
$$

where the parameters $\lambda$ work as Lagrange multipliers that average the regularization contributions of the objective function. The parameter $\lambda_{D}$ acts on all model parameters and its purpose is to average the model parameter updates. $\lambda_{R}$ controls the smoothing degree over the reflector. The parameter $\lambda_{\text {Lap }}$ determines the smoothing of the isotropic curvatures (Laplacian). The parameters $\lambda_{C 1}$ and $\lambda_{C 3}$ determine the curvature in the horizontal and vertical directions, respectively, while the parameters $\lambda_{G 1}$ and $\lambda_{G 3}$ determine the gradient in the horizontal and vertical directions, respectively. In this work, the value of each regularization parameter is varied gradually, keeping the other parameters constant. The objective is to analyze the influence of each regularization parameter in the solution of the inverse problem. The behavior of the estimated model parameters is analyzed through the RMS data error, and the absolute error is computed in terms of slowness, position and traveltime. We have to be aware that the adoption of several regularization constraints together with their regularization parameters in the construction of the objective function will increase the level of non-linearity of the inverse problem.

\section{OPTIMIZATION IN STEREOTOMOGRAPHY}

As in traditional traveltime tomography, a non-linear, iterative, local optimization scheme, is used to update the estimated model stereotomography. Quasi-Newton optimization methods have been used until the present time, which require the calculation of Fréchet derivatives of the data in relation to the model $\boldsymbol{m}$. The calculation of the Fréchet derivative is detailed in Billette \& Lambaré (1998). It is based on paraxial ray tracing (Farra \& Madariaga, 1987) and requires a bit of softness in the velocity macro-model.

In these local optimization methods, first ray segment pairs are optimized from a defined initial velocity model. This step is called localization. It can be seen as a generalization of the kinematic migration, for example, Guillaume et al. (2001). The same cost function for global updating is used but with a fixed velocity model, and with an independent procedure only the ray segment parameters are optimized to fit the source and receiver positions, the double traveltime and the inclinations. 
In a standard common offset kinematic migration, only the slopes in common offset gathers are considered. An a priori covariance matrix is used, which is a diagonal matrix containing the square errors for each observed data parameter. According to Billette et al. (2003), the stereotomographic algorithm consists of three steps, as illustrated in Figure 2.

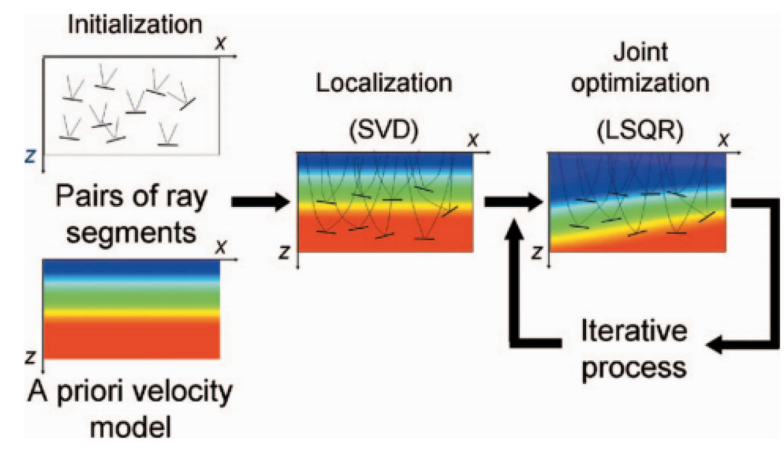

Figure 2 - Diagram for the non-linear stereotomographic optimization. After the adoption of an initial model (velocities and rays), the first optimization step is a localization where the ray segment pairs are rearranged iteratively in the initial velocity model. The misfit function is minimized and the joint optimization is performed with a gradient method (LSQR). Adapted from Lambaré (1998).

(1) Construction of the initial model, that is, the ray segment pairs and the velocity model. In practice, simple initial models are used, e.g., a homogeneous velocity model and ray segments derived from simple geometrical considerations.

(2) Event localization in the initial velocity model. This is done using a Quasi-Newton nonlinear optimization, where all events can be located independently, using, for example, singular value decomposition. The location phase leads to a significant reduction in the cost function.

(3) Joint iterative inversion of ray segments and velocity model parameters. This is accomplished using the LSQR method (Paige and Saunders, 1982). The LSQR optimization scheme is widely used for seismic tomography problems because it is well suited for tomographic problems with large and sparse Fréchet derivative matrices. A Laplacian regularization term is introduced to the velocity model.

\section{APPLICATION TO THE MARMOUSOFT DATA}

We used the Marmousoft data which was adapted by Billete \& Lambaré (1998) from the 2-D Marmousi synthetic data, where they used ray modeling with Born approximation from a data set free from multiple and refractions (Fig. 3).
The Marmousoft is the combination of a smoothed velocity field and a complex reflectivity. Originally created by the French Petroleum Institute for the European Association of Exploration Geophysicists meeting in 1990, this model was developed to be geologically plausible and complex to ensure the presence of various reflectors, high dips and strong velocity gradients, both vertical and lateral. The data acquisition was modeled by a program that simulates a seismic line with records from different sources. The first and the last source position are 3.75 and $9.975 \mathrm{~km}$, respectively. The distance between shots is $0.075 \mathrm{~km}$. The distance between receivers is $0.075 \mathrm{~km}$, the first one being located at $1.425 \mathrm{~km}$ the last one at $9.75 \mathrm{~km}$ and all of them with a constant depth of $1.01 \mathrm{~km}$.

The stereotomographic program is based on ray theory using linear iterations around a reference model for building an estimated velocity model. The first step in the process was to collect the picks using an automatic selection tool, which provided a total of 5,490 locally coherent events, containing source and receiver positions, estimates for traveltimes and horizontal slowness components (slopes measured in the events). In the first set of iterations, with a $13 \times 11$ less dense mesh, the initial model was a gradient-type velocity field. The result of these iterations is the final model, with a $49 \times 21$ denser B-spline mesh, with nodes spaced at $0.25 \mathrm{~km}$, laterally and vertically. The inversion algorithm ends after reaching the maximum number of 30 iterations, and then the models are resampled in a $243 \times 767$ mesh, where nodes are spaced at $12 \mathrm{~m}$ both laterally and vertically.

\section{ANALYSIS OF REGULARIZATION PARAMETERS}

For each regularization parameter, different inversions were performed gradually varying the value of the analyzed parameters while keeping the other parameters constant. It was therefore possible to assess the contribution of each parameter separately. The chosen methodology to evaluate the inversion sensitivity to regularization parameters was the construction of the L-curve, the L-module curve, in addition to obtaining the RMS errors of the data and the absolute deviations of the estimated model parameters in relation to the true ones.

The parameter $\lambda_{D}$ acts on all model parameters and its purpose is to average the model parameter updates. Table 1 shows the simulation results, where $\lambda_{D}$ was the only parameter to be varied and all the other parameters were kept constant and equal to zero.

The L-curve in Figure 4 shows that for small values of $\lambda_{D}$, the inversion is minimally sensitive with respect to the calculated 


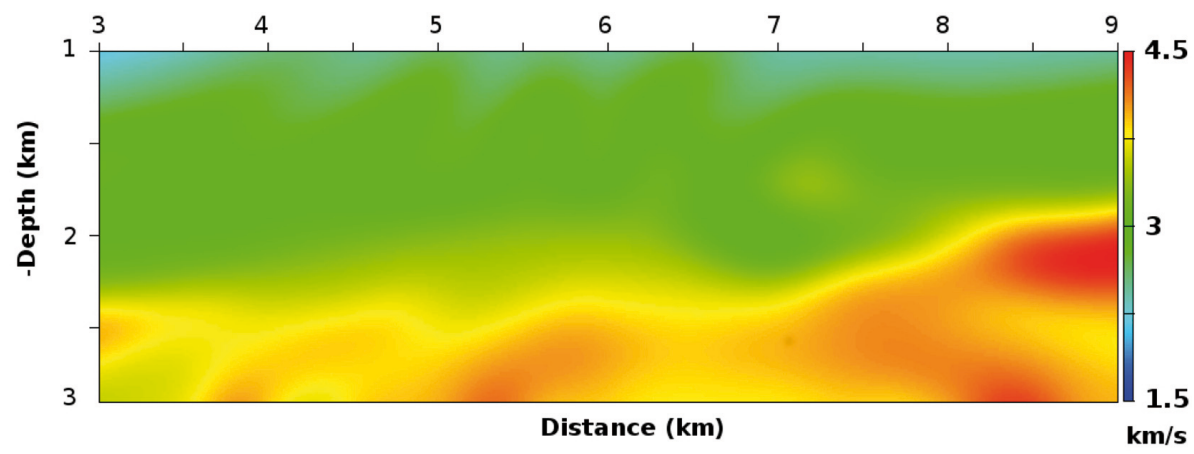

Figure 3 - Investigation area for stereotomography in the Marmousoft synthetic model.

Table 1 - Stereotomography inversion results in relation to the variation of parameter $\lambda_{D}$ $E_{d}$ is the RMS error between the observed and the calculated data, and $\delta_{v}$ is the absolute error between the true slowness and the estimated slowness (in s/km).

\begin{tabular}{|c|c|c|c|c|c|}
\hline$\lambda_{D}$ & $E_{d}(\%)$ & $\delta_{v}$ & $\left\|\boldsymbol{D}_{1}^{0} \boldsymbol{m}\right\|_{2}^{2}$ & $\left\|\boldsymbol{d}^{\text {obs }}-\boldsymbol{d}^{\text {cal }}\right\|_{2}^{2}$ & ModL \\
\hline 0.01 & 0.1518 & 0.0026 & 347.6533 & 0.2976 & 347.6534 \\
0.05 & 0.2072 & 0.0035 & 344.4127 & 0.4063 & 344.4129 \\
0.06 & 0.2271 & 0.0038 & 344.3345 & 0.4452 & 344.3348 \\
0.07 & 0.2412 & 0.0041 & 344.2937 & 0.4739 & 344.2940 \\
0.08 & 0.2545 & 0.0043 & 344.2661 & 0.4984 & 344.2665 \\
0.09 & 0.2649 & 0.0045 & 344.2475 & 0.5193 & 344.2479 \\
0.10 & 0.2747 & 0.0046 & 344.2332 & 0.5386 & 344.2336 \\
1.00 & 0.5477 & 0.0088 & 344.0620 & 1.0736 & 344.0637 \\
4.00 & 1.0953 & 0.0125 & 344.0884 & 2.1471 & 344.0951 \\
7.00 & 1.3520 & 0.0134 & 344.1251 & 2.6503 & 344.1353 \\
10.00 & 1.6114 & 0.0133 & 344.1428 & 3.1588 & 344.2433 \\
\hline
\end{tabular}

data; that is, for $\lambda_{D}$ less than 0.06 , the variation in the regularization parameters has little influence on the observed data. However, in this same region, there is great sensitivity in the inversion in relation to the estimated model parameters; that is, minor variations in $\lambda_{D}$ lead to large variations in the estimated velocity field. For larger values of $\lambda_{D}$, above 7.0 , the behavior is the opposite; the inversion becomes quite sensitive with respect to the observed data calculated and very stable in relation to the estimated velocity field. This behavior is expected, as we saw in the section on the L-curve. Between $\lambda_{D}=0.06$ and $\lambda_{D}=7.0$, in the knee of the L-curve, there is an equilibrium point with a trade-off between the terms of the objective function. To identify this point more clearly the L-module criterion was used, as shown in Figure 5 , where it is easier to observe that the equilibrium point corresponds to $\lambda_{D} \cong 1$. Figure 6 shows the estimated model using this regularization parameter.
The parameter $\lambda_{L a p}$ determines the smoothing of the isotropic curvatures (Laplacian), acting directly on the velocity model. During the computer simulations in which $\lambda_{L a p}$ was varied, keeping the remaining regularization parameters equal to zero, it was observed that the inversion did not converge. Thus, it was decided to keep $\lambda_{D}=1$ and vary $\lambda_{L a p}$, leaving the other parameters constant and equal to zero, as seen in Table 2.

The results show that the stereotomographic inversion was less sensitive to the regularization parameter $\lambda_{L a p}$, as seen in Table 2 and Figure 7 . It was observed that both data and model parameters vary little with the gradual variation of $\lambda_{\text {Lap }}$. For example, for all used values of $\lambda_{\text {Lap }}$, the absolute deviation in slowness had no variation to the fourth decimal figure, remaining equal to $0.0088 \mathrm{~s} / \mathrm{km}$ in all simulations. The L-curve was not effective in this part, in such a way that we used the L-module criterion (Fig. 7), which had a very stable performance with lit- 


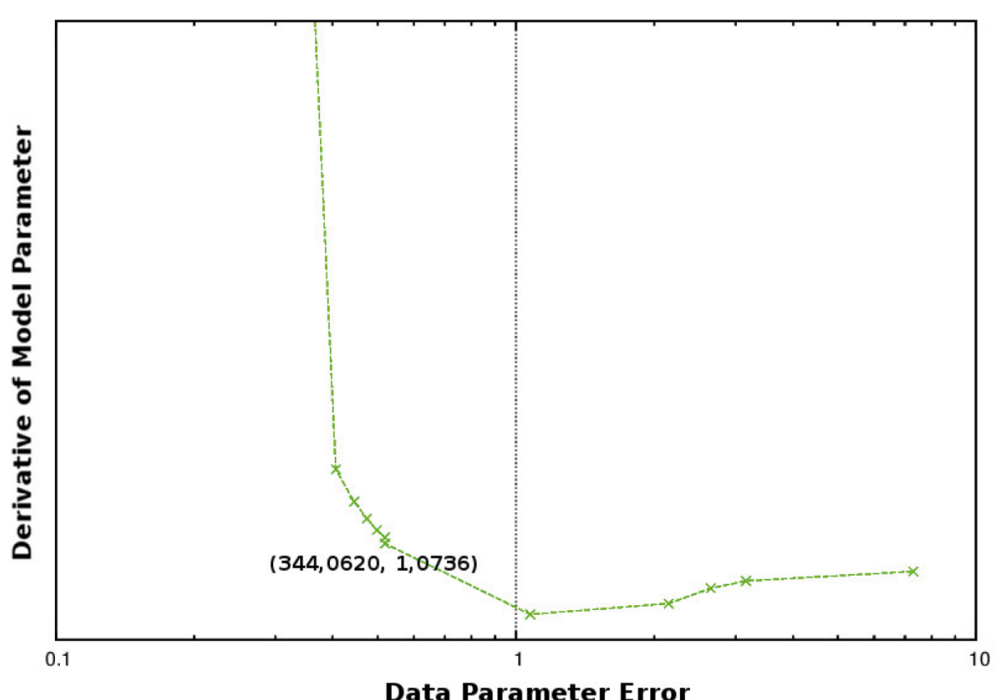

Figure 4 - L-curve for the selection of the regularization parameter $\lambda_{D}$.

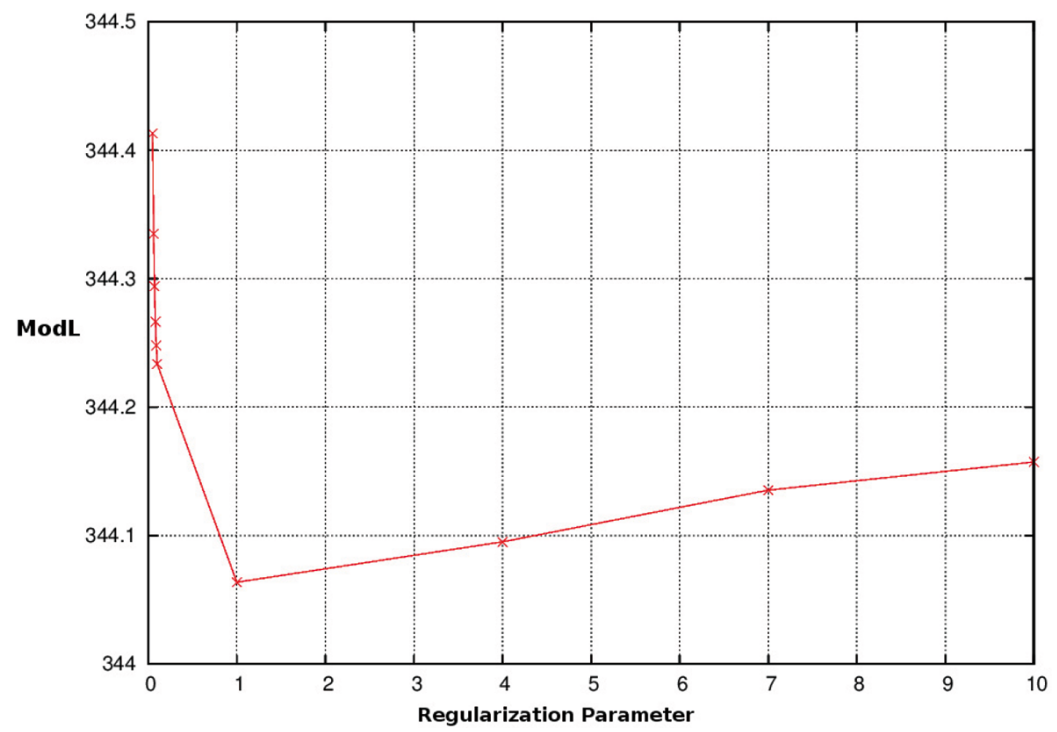

Figure 5 - L-module for the selection of the regularization parameter $\lambda_{D}$. The curve has its minimum in $\lambda_{D}=1$.

tle change in the $y$-axis between $\lambda_{\text {Lap }}=0$ and $\lambda_{\text {Lap }}=0.09$. The L-module curve has its minimum in $x \lambda_{L a p}=2$ and then grows with a steeper slope. Figure 8 shows the velocity distribution obtained with $\lambda_{\text {Lap }}=2$ which can be considered quite satisfactory when compared to the exact model in Figure 1. The RMS data error is $0.5474 \%$, and the absolute deviation in the estimated slowness is $0.0088 \mathrm{~s} / \mathrm{km}$.

The parameter $\lambda_{C 1}$ determines the curvature in relation to the $x$ direction and as for the parameter $\lambda_{\text {Lap }}$, it was necessary to keep $\lambda_{D}=1$ to guarantee the convergence. Table 3 shows the results, where the parameter $\lambda_{C 1}$ varied while $\lambda_{D}=1$ and the other parameters were constant and equal to zero. The inversion proved to be very sensitive in general to $\lambda_{C 1}$. The built L-curve exhibited typical behavior, as seen in Figure 9. At first, between $\lambda_{C 1}=0.001$ and $\lambda_{C 1}=10.0$, the modulus of the model parameter derivative is very stable or varies very little with the variation of $\lambda_{C 1}$. On the other hand, the modulus of the data error vector varies greatly in the same region. Between $\lambda_{C 1}=100$ and $\lambda_{C 1}=30,000$, the behavior is reversed; that is, the modulus of the data error vector is stable, and the modulus of the model parameter derivative becomes very sensitive. From this point, $\lambda_{C 1}=30,000$, the curve reaches its knee. 


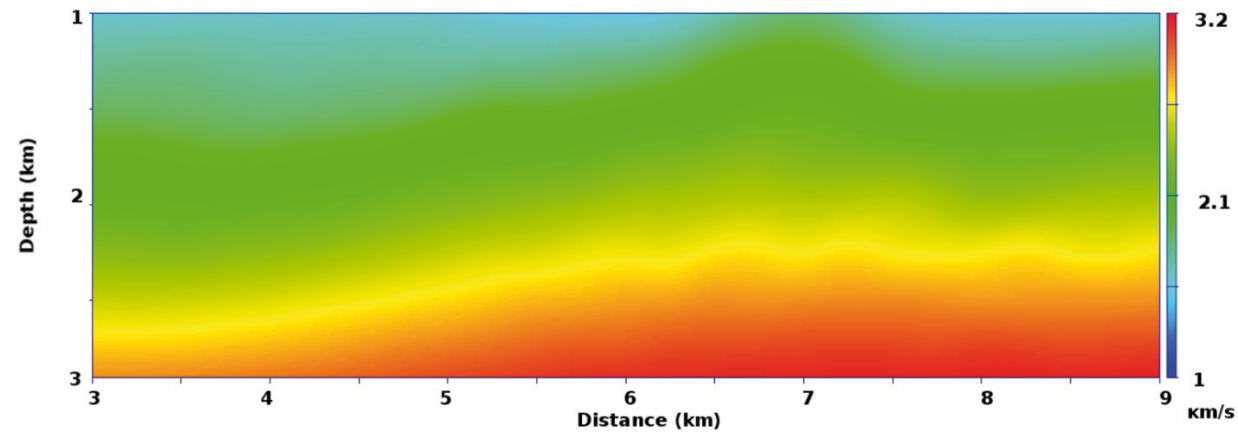

Figure 6 - Estimated model using $\lambda_{D}=1$ and the other parameters equal to zero. The RMS error in data was $E_{d}=0.5477 \%$.

Table 2 - Stereotomography inversion results in relation to the variation of parameter $\lambda_{L a p}$. $E_{d}$ is the RMS error between the observed and the calculated data, and $\delta_{v}$ is the absolute error between the true slowness and the estimated slowness (in $\mathrm{s} / \mathrm{km}$ ).

\begin{tabular}{|c|c|c|c|c|c|}
\hline$\lambda_{\text {Lap }}$ & $E_{d}(\%)$ & $\delta_{v}$ & $\left\|\left(\boldsymbol{D}_{1}^{2}+\boldsymbol{D}_{3}^{2}\right) \boldsymbol{m}\right\|_{2}^{2}$ & $\left\|\boldsymbol{d}^{\text {obs }}-\boldsymbol{d}^{\text {cal }}\right\|_{2}^{2}$ & ModL \\
\hline 0.001 & 0.5477 & 0.0088 & 5.0127 & 1.0736 & 5.1264 \\
0.010 & 0.5477 & 0.0088 & 5.0125 & 1.0736 & 5.1262 \\
0.030 & 0.5477 & 0.0088 & 5.0124 & 1.0736 & 5.1261 \\
0.050 & 0.5477 & 0.0088 & 5.0128 & 1.0736 & 5.1265 \\
0.070 & 0.5476 & 0.0088 & 5.0127 & 1.0735 & 5.1226 \\
0.090 & 0.5476 & 0.0088 & 5.0125 & 1.0735 & 5.1262 \\
1.000 & 0.5478 & 0.0088 & 5.0020 & 1.0735 & 5.1160 \\
2.000 & 0.5474 & 0.0088 & 4.9885 & 1.0730 & 5.1026 \\
3.000 & 0.5469 & 0.0088 & 4.9896 & 1.0721 & 5.1035 \\
4.000 & 5.4688 & 0.0088 & 5.0129 & 1.0720 & 5.1262 \\
10.000 & 0.5518 & 0.0088 & 5.3406 & 1.0818 & 5.4491 \\
\hline
\end{tabular}

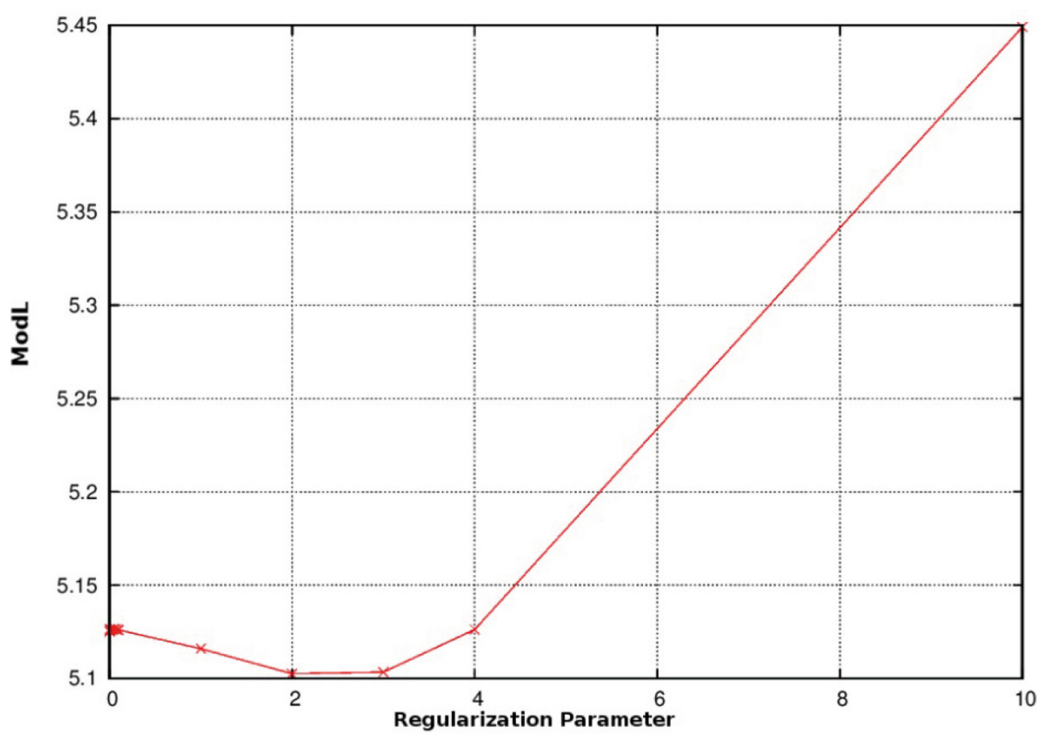

Figure 7 - L-module for the selection of the regularization parameter $\lambda_{L a p}$. The curve has its minimum in $\lambda_{L a p}=2$. 


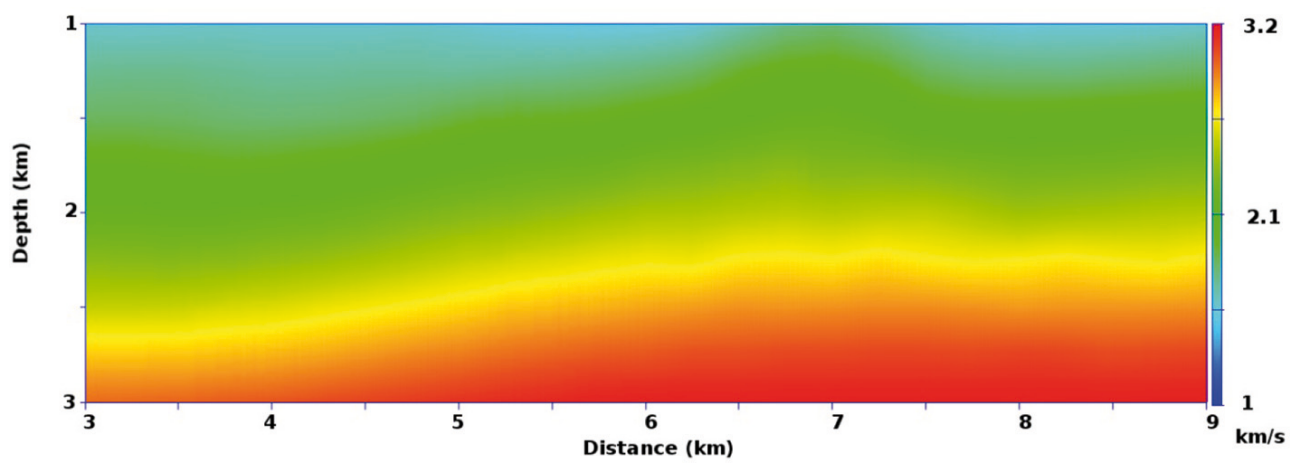

Figure 8 - Estimated model using $\lambda_{D}=1, \lambda_{L a p}=2$ and the other parameters equal to zero. The RMS error in the data was $E_{d}=0.5474 \%$.

Table 3 - Stereotomography inversion results in relation to the variation of parameter $\lambda_{C 1}$. $E_{d}$ is the RMS error between the observed and the calculated data, and $\delta_{v}$ is the absolute error between the true slowness and the estimated slowness (in $\mathrm{s} / \mathrm{km}$ ).

\begin{tabular}{|c|c|c|c|c|c|}
\hline$\lambda_{\text {Lap }}$ & $E_{d}(\%)$ & $\delta_{v}$ & $\left\|\left(\boldsymbol{D}_{1}^{2}+\boldsymbol{D}_{3}^{2}\right) \boldsymbol{m}\right\|_{2}^{2}$ & $\left\|\boldsymbol{d}^{\text {obs }}-\boldsymbol{d}^{\text {cal }}\right\|_{2}^{2}$ & ModL \\
\hline 0.001 & 0.5477 & 0.0088 & 198.2591 & 1.0736 & 198.2620 \\
0.010 & 0.5477 & 0.0088 & 198.2646 & 1.0737 & 198.2675 \\
0.100 & 0.5943 & 0.0096 & 198.2605 & 1.1651 & 198.2639 \\
1.000 & 1.2764 & 0.0210 & 198.5747 & 2.5021 & 198.5905 \\
10.000 & 1.6454 & 0.0266 & 198.4731 & 3.2255 & 198.4993 \\
200.000 & 1.6371 & 0.0266 & 197.7518 & 3.2094 & 197.7778 \\
$10,000.000$ & 1.6009 & 0.0264 & 197.7064 & 3.1383 & 197.8357 \\
$30,000.000$ & 1.6539 & 0.0271 & 197.3427 & 3.2422 & 197.3693 \\
$50,000.000$ & 1.6993 & 0.0277 & 197.3281 & 3.3312 & 197.3562 \\
$80,000.000$ & 1.7986 & 0.0289 & 197.3268 & 3.5259 & 197.3583 \\
$100,000.000$ & 1.9116 & 0.0302 & 197.3276 & 3.7473 & 197.3632 \\
\hline
\end{tabular}

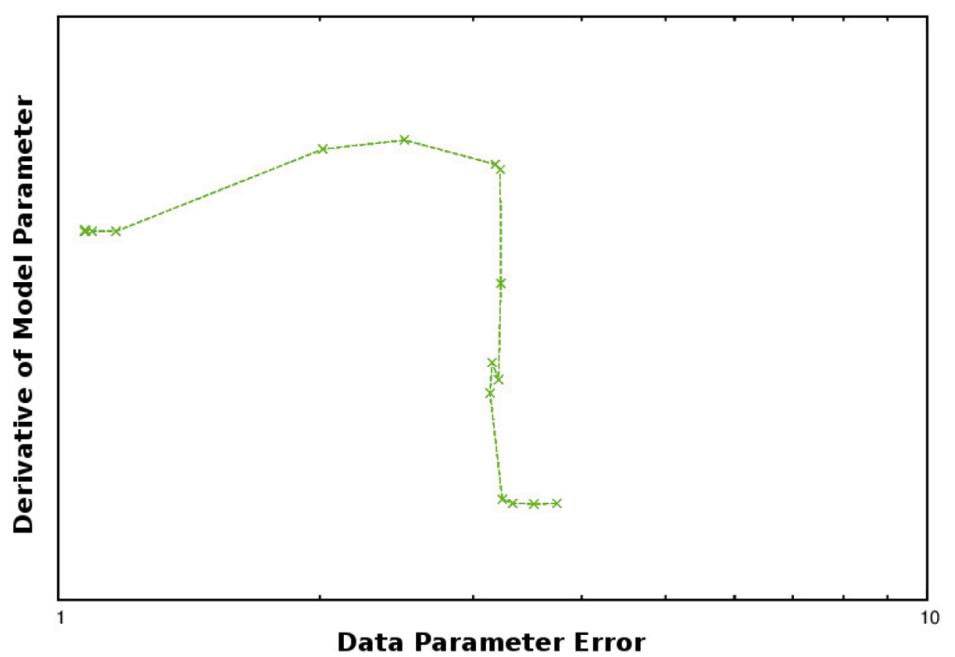

Figure 9 - L-curve for the selection of the regularization parameter $\lambda_{C 1}$. The curve has its knee between $\lambda_{C 1}=30,000$ and $\lambda_{C 1}=100,000$. 


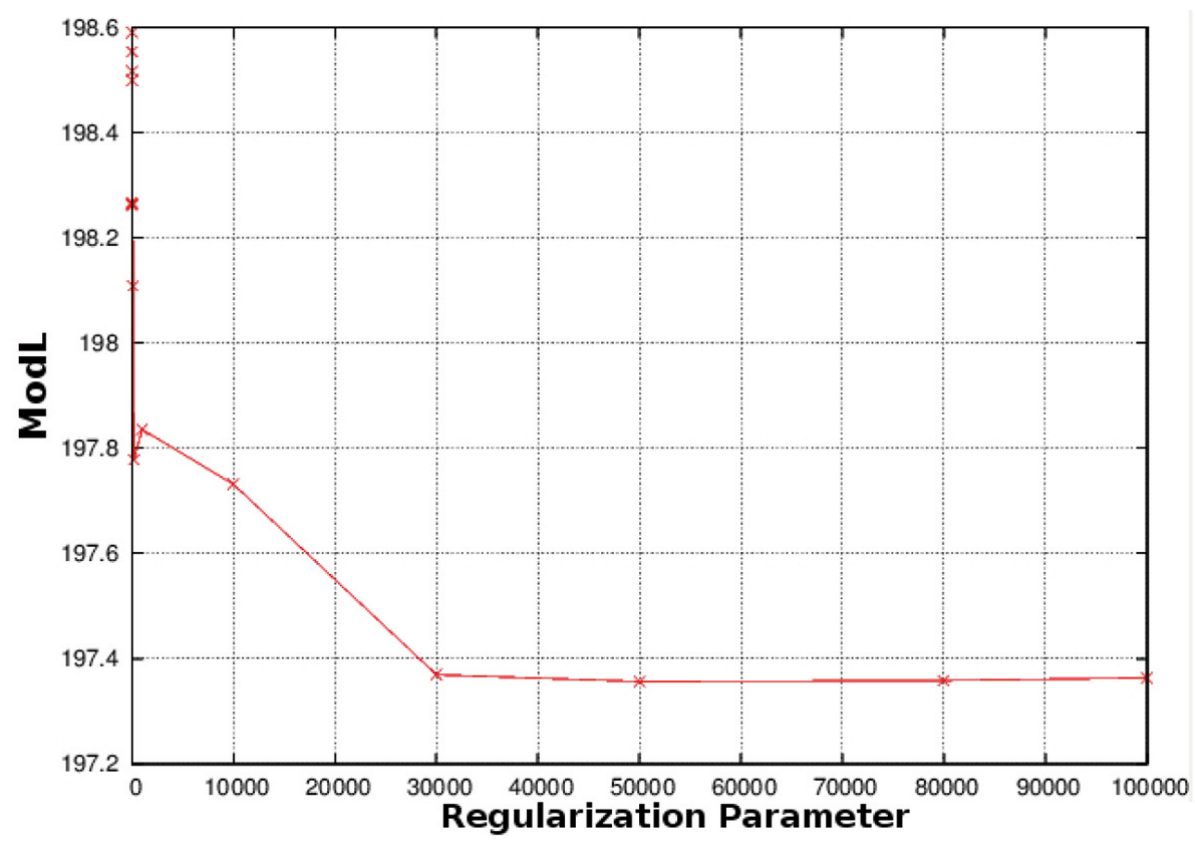

Figure 10 - L-module for the selection of the regularization parameter $\lambda_{C 1}$. The curve has its minimum in $\lambda_{C 1}=30,000$.

The L-module curve in Figure 10 confirms the results shown by the $L$-curve. We see a very sharp variation in ModL in the beginning of the L-module curve and some stabilization from $\lambda_{C 1}=$ 30,000, where the L-curve has its knee. The curve has its minimum value at $\lambda_{C 1}=50,000$.

The parameter $\lambda_{C 3}$, as the parameter $\lambda_{C 1}$, determines the curvature but in relation to the $z$ direction, acting directly on the velocity field. Again, it was necessary to keep $\lambda_{D}=1$ to guarantee the convergence, while the other parameters were constant and equal to zero. Table 4 shows that in general, the inversion proved to be reasonably sensitive to changes in $\lambda_{C 3}$. At the beginning, there is very little response in the data with the variation of the regularization parameter and, at the same time, a higher response in the derivatives of the model parameters in the same range. Soon after, between $\lambda_{C 3}=0.1$ and $\lambda_{C 3}=$ 0.5 , there is a sudden variation in the calculated data, which can be seen in $E_{d}, \delta_{v}$ and $\left\|\boldsymbol{d}^{\text {obs }}-\boldsymbol{d}^{\text {cal }}\right\|_{\mathbf{2}}^{\mathbf{2}}$ and is also apparent in Figures 11 and 12 . The parameters proved to be slightly more stable, with a higher sensitivity at the beginning, as already stated, and a lower sensitivity after the L-curve knee. From the L-module curve, one can see that the minimum value of ModL was around $\lambda_{C 3}=0.1$.

The parameter $\lambda_{G 1}$ acts directly on the velocity field and determines the gradient with respect to the $x$ direction. In this step, $\lambda_{G 1}$ was varied keeping $\lambda_{D}=1$ and the remaining pa- rameters constant and equal to zero, as seen in Table 5 . The constructed L-curve showed an unusual behavior and was not used in this analysis. The inversion was sensitive to the variation of $\lambda_{G 1}$ in relation to the calculated data and insensitive with respect to the estimated model parameters for the first two $\lambda_{G 1}$ parameters. As for the last three values of $\lambda_{G 1}$, from $\lambda_{G 1}=1$ to $\lambda_{G 1}=100$, the behavior is reversed.

\section{CONCLUSIONS}

The use of regularization in stereotomography is essential for inversion success. Without regularization, the iterations tend not to converge, as observed in this work. We also observed that stereotomographical inversion is relatively more sensitive to some regulation parameters. For $\lambda_{L a p}$, there was little sensitivity with the L-curve with a very unusual format. For the other regularization parameters, the inversion is in general very sensitive, with some small differences in behavior in regions within the respective L-curves.

Most regularization parameters only worked when used in conjunction with another parameter because when they were acting alone, the inversion procedure did not converge. On the other hand, $\lambda_{D}$ was the only regularization parameter that could be used without the aid of another, allowing the iterations to converge. The use of methods such as the L-curve and L-module curve were very satisfactory for the analysis of the influences of 
Table 4 - Stereotomography inversion results in relation to the variation of parameter $\lambda_{C 3}$. $E_{d}$ is the RMS error between the observed and the calculated data, and $\delta_{v}$ is the absolute error between the true slowness and the estimated slowness (in $\mathrm{s} / \mathrm{km}$ ).

\begin{tabular}{|c|c|c|c|c|c|}
\hline$\lambda_{C 3}$ & $E_{d}(\%)$ & $\delta_{\boldsymbol{v}}$ & $\left\|\boldsymbol{D}_{3}^{2} \boldsymbol{m}\right\|_{2}^{2}$ & $\left\|\boldsymbol{d}^{\text {obs }}-\boldsymbol{d}^{\text {cal }}\right\|_{2}^{2}$ & ModL \\
\hline 0.001 & 0.5476 & 0.0088 & 5.0090 & 1.0735 & 5.1227 \\
0.010 & 0.5455 & 0.0088 & 4.8242 & 1.0693 & 4.9413 \\
0.050 & 0.5707 & 0.0088 & 3.8784 & 1.0927 & 4.1257 \\
0.100 & 0.6707 & 0.0099 & 3.2121 & 1.3148 & 3.4708 \\
0.500 & 5.0295 & 0.0750 & 5.4986 & 9.8595 & 11.2891 \\
1.000 & 5.5656 & 0.0911 & 5.1201 & 10.9105 & 12.0522 \\
10.000 & 5.6390 & 0.0935 & 4.7751 & 11.0543 & 12.0416 \\
100.000 & 5.8057 & 0.0975 & 4.2205 & 11.3811 & 12.1385 \\
\hline
\end{tabular}

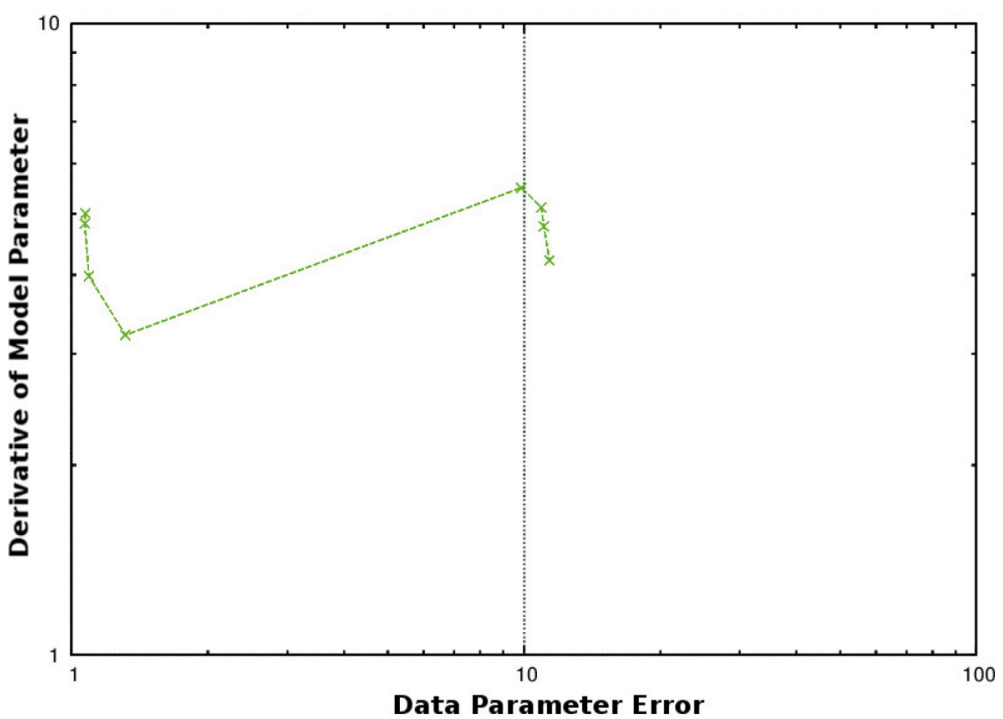

Figure 11 - $\mathrm{L}$-curve for the selection of the regularization parameter $\lambda_{C 3}$. The curve has its knee between $\lambda_{C 3}=0.01$ and $\lambda_{C 3}=0.1$.

Table 5 -Stereotomography inversion results in relation to the variation of parameter $\lambda_{G 1} . E_{d}$ is the RMS error between the observed and the calculated data, and $\delta_{v}$ is the absolute error between the true slowness and the estimated slowness (in s/km).

\begin{tabular}{|c|c|c|c|c|c|}
\hline$\lambda_{G 1}$ & $E_{d}(\%)$ & $\delta_{\boldsymbol{v}}$ & $\left\|\boldsymbol{D}_{1}^{1} \boldsymbol{m}\right\|_{2}^{2}$ & $\left\|\boldsymbol{d}^{\text {obs }}-\boldsymbol{d}^{\text {cal }}\right\|_{2}^{2}$ & ModL \\
\hline 0.001 & 0.5477 & 0.0088 & 137.6565 & 1.0737 & 137.6607 \\
0.010 & 0.5605 & 0.0090 & 137.6511 & 1.0988 & 137.6555 \\
0.100 & 0.8114 & 0.0132 & 137.5680 & 1.5907 & 137.5772 \\
1.000 & 1.2603 & 0.0203 & 137.7353 & 2.4705 & 137.7575 \\
10.000 & 1.2645 & 0.0196 & 137.8133 & 2.2828 & 137.8322 \\
100.000 & 1.2657 & 0.0196 & 137.6725 & 2.2851 & 137.6915 \\
\hline
\end{tabular}

each regularization parameter, as well as for the choice of the optimum parameter. The L-curve makes is possible to observe the behavior of the calculated data and the estimated model simulta- neously, whereas the L-curve module provides a greater certainty equilibrium point and requires a smaller number of points when compared to the L-curve. 


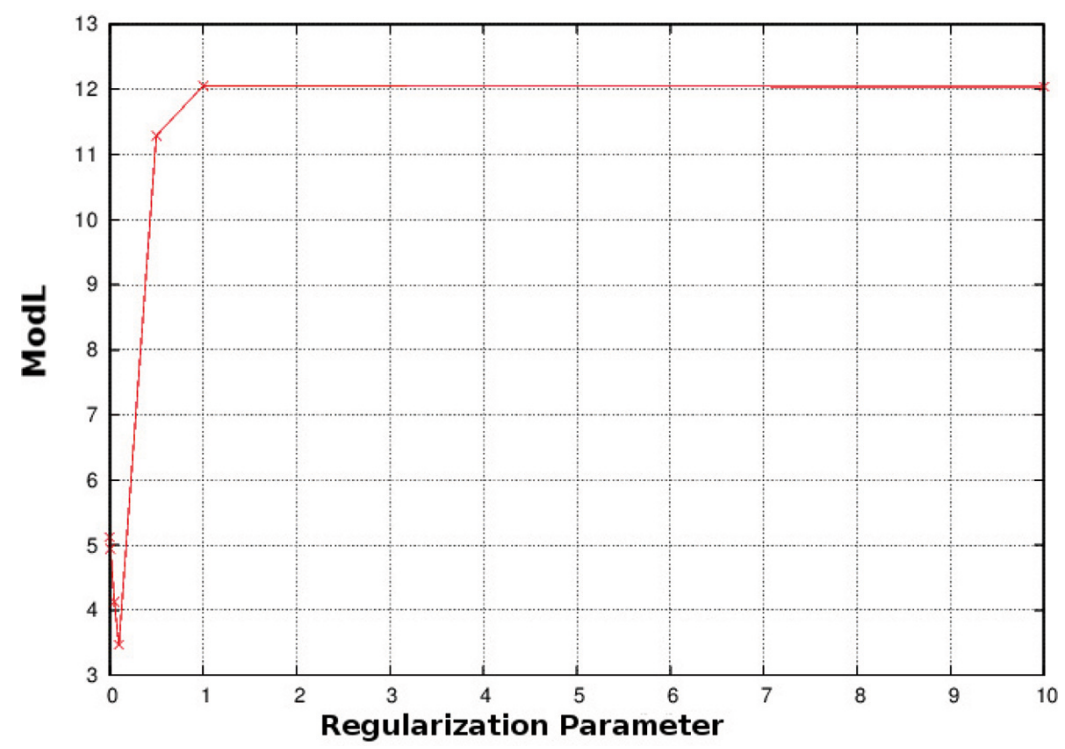

Figure 12 - L-module for the selection of the regularization parameter $\lambda_{C 3}$. The curve has its minimum in $\lambda_{C 3}=0.1$.

\section{ACKNOWLEDGEMENTS}

J.R. Silva thanks CNPq for the M.Sc. scholarship. J.C. Costa and $A$. Bassrei thank CNPq for their research fellowship projects. The authors thank CNPq and PETROBRAS for the support to National Institute of Science and Technology of Petroleum Geophysics (INCT-GP), and FINEP for the support to Research Network in Exploration Geophysics (Rede 01).

\section{REFERENCES}

BILLETTE F, LE BÉGAT S, PODVIN P \& LAMBARÉ G. 2003. Practical aspects and applications of 2D stereotomography. Geophysics, 68 : 1008-1021.

BILLETTE F \& LAMBARÉ G. 1998. Velocity macro-model estimation by stereotomography. Geophysical Journal International, 135: 671-680.

COSTA JC, SILVA FJC, GOMES ENS, SCHLEICHER J, MELO A \& AMAZONAS D. 2008. Regularization in slope tomography. Geophysics, 73(5): VE39-VE47.

LAMBARÉ G. 1998. Stereotomography: past, present and future. CSEG Recorder, April, 47-51.

MENKE W. 1989. Geophysical Data Analysis: Discrete Inverse Theory. rev. ed. Academic Press, San Diego, 289 pp.

PAIGE CC \& SAUNDERS MA. 1982. LSQR: An algorithm for sparse linear equations and least squares. Association of Computing Machines
Transactions on Mathematical Software, 8: 43-71.

RIABINKIN LA. 1991. Fundamentals of resolving power of controlled directional reception (CDR) of seismic waves, in slant stack processing. In: GELDART L \& SHERIFF RE (Eds.). Slant Stack Processing. Society of Exploration Geophysicists, Tulsa, p. 36-60.

SWORD C. 1987. Tomographic determination of interval velocities from reflection seismic data: the method of controlled directional reception. Ph.D. Dissertation, Stanford University, 196 pp.

SÁ TJM. 1996. Inversão e seleção de imagens na tomografia de transmissão utilizando regularização de ordem arbitrária, decomposição em valores Singulares, conjugado gradiente modificado e entropia. Master Dissertation, Universidade Federal da Bahia, Bahia, Brazil. 108 pp.

SANTOS ETF, BASSREI A \& COSTA JC. 2006. Evaluation of L-curve and $\Theta$-curve approaches for the selection of regularization parameter in anisotropic traveltime tomography. Journal of Seismic Exploration, 15: 245-272.

TARANTOLAA. 2005. Inverse Problem Theory: Methods for Data Fitting and Model Parameter Estimation. SIAM, Philadelphia, 342 pp.

TERRAFA, COSTA JC \& BASSREI A. 2012. Stereotomography for velocity model estimation in seismic imaging: application to real data from Jequitinhonha sedimentary basin. Brazilian Journal of Geophysics, 30(4): 473-482. 